\title{
Integrating Sustainability into Conventional Construction Contracts in Egypt
}

\author{
Manal S. Abdelhamid \\ ${ }^{I}$ (Associate Professor, Construction Research and Project Management Institute, Housing and Building \\ National Research Center (HBRC))
}

\begin{abstract}
Recently the concept of sustainability has wide interest at the academic level in Egypt, but modestly approached at practice levels. As a result of that a big number of researches and national studies have been published and developed. Egyptian construction sector has taken more practical steps by issuing a national rating system and developing related codes. However, conventional contracts as the reinforcement tool of project management do not reflect this interest and more over it could be an obstacle that hindering its implementation in construction projects in Egypt. The current research focuses on Construction waste management (CWM) as one of the sustainability aspects and one of the most irritating problems in Egypt. It explores through its undertaken methodology how to integrate these recently adopted concepts and procedures in Egypt into the conventional construction contract in order to deliver a sustainable construction project with respect to CWM. The research investigates the influence of contract type and/or project delivery method on sustainable projects. The current paper develops a Contractual Relation Guideline CRG to assess in formulating sustainable contract focused on CWM. The drives of CRG are appropriate contract approaches Sustainability clauses and factors to be considered by stakeholders as guidance for achieving sustainable construction in Egypt.
\end{abstract}

Keywords: - Contract Type, Construction waste management, Contractual relation, Management tool, Sustainability,

\section{INTRODUCTION}

In the developed countries, the sustainable principals have been widely discussed and practiced and the sustainability issues translated into contractual requirements in the construction sector [1]. However there is a real need for integrating sustainable principals into construction management practices in the developing world. For instance, a recent research shows that Sustainability in the Middle East is faced by many challenges; particularly the absence of green benchmarking and regulations which hampers green design [2]. Findings from literature review represented in thesis [3], National [4] \& international [5] studies and published papers [6] clearly demonstrate that C\&D waste is a major challenge facing the sustainability of construction sector in Egypt and most of them introduce frameworks, procedures and management systems that help in handling the waste. However these studies and many others that focused on sustainability issues in Egypt did not pay attention to the contract as an essential management tool for organizing and implementing the proposed systems. Even though Egypt has remarkable steps towards sustainability in Egyptian construction sector at the academic level represented in issuing the national rating system "Green Pyramid Rating System" and in the process of developing related codes such that "Code of Green Building "and "Code of Solid Waste Recycling" "However construction contracts typically do not address this crucial issue. Integrating these recently adopted concepts and procedures of sustainability in Egypt into the traditional construction contract is believed to change construction practices to be more sustainable and to comply with the codes and standards of sustainability. The current research discusses the impact of the management practices on adopting and implementing sustainable principles in Egyptian construction sector. The research emphasizes on the contract as a reinforcement tool of project management practices and on CWM as one of the sustainability aspects in construction sector..For the purpose of the current research the author refers to the contract that does not consider the sustainability principals and CWM as conventional contracts (CC) and the one that consider CWM as sustainable contract (SC).It is also worth to mention that the research use the term "sustainable" to refer to whatever considers CWM .

\section{WHY CONTRACTS}

A large number of researches address the significance of contract as a management tool. In a research [7] that focused on the critical factors (CFs) and their relative importance to whole life performance assessment of construction projects, it has been concluded that "Clarity of contract in scope is identified as one of the performance attributes". The study shows that it has a significant impact on the project and it has been 
ranked the most important out of the top $80 \mathrm{CFs".} \mathrm{"from} \mathrm{a} \mathrm{traditional} \mathrm{construction} \mathrm{and} \mathrm{a} \mathrm{green} \mathrm{construction}$ perspectives, it is not only the difference in project management but also how important project management is and what needs to be done" is the argument of a study [8] that had developed a matrix that present specific adjustments to traditional project management practices based on the project management life cycle and emphasized the contractual related aspects such that Initial budget and schedule, construction documents development, project bidding and contracting as the most significant adjustments to project management practices necessary for delivering a green construction project within acceptable budgetary parameters. To assess the factors that influences the waste management performance in construction projects, another study [9] has identified five different categories, among them "management practice" that was ranked as the second most important one, in the "Management practice" category, 16 factors are listed in relation to the contractor's waste management plan and execution approach, contractual conditions for waste treatment, as well as the contractor's supervision of waste control. The previous literature review shows that the contract represents a significant management tool that strongly influences the project performance. The choice of an appropriate contract facilitates a process that allows the parties to achieve superior performance [10].Contract and project delivery approach are tow faces for the same coin, so CWM problem cannot be completely and sufficiently addressed without considering the influence of project delivery approaches. The choice of method of Procurement of a building can influence its greenness and sustainability [1].

\section{RESEARCH OBJECTIVES}

The main objective of this research is to establish a Contractual Relation Guidelines CRG to assess stakeholders in developing a sustainable contract for the green project in Egypt. The secondary objective that support the main one is investigating the influence of contract type and/or project delivery method on achieving green construction projects. This objective is aimed to be achieved through answering the following questions: To what extent sustainability concepts and procedures are practiced in construction sector? , How sustainability issues are tackled in construction project contracts in Egypt?, Why contract? Is it contract and/or project delivery method?, does the contract type and/or project delivery method influence the delivery of green projects? , and finally what are the essential requirements for a sustainable contract?

\section{METHODOLOGY}

The research subject is considerably new worldwide and particularly in Egypt therefore the research methodology is based on the exploratory approach through the following two stages; first stage is devoted to identifying the gap between the progress at the academic level in CDWM in Egypt and the practice level in Egyptian construction firms to subjectively justify the urgency of the current research. This is reached by evaluating the practice level of CWM through surveying a representative sample of construction projects in Egypt. A closed questions questionnaire was designed to explore how CWM is addressed, and practiced in the conventional contracted based projects. The questionnaire was applied on a sample of 60 construction projects in great Cairo as a part of a study [3] under the author supervision. The questions investigate the following four points: CWM in contract clauses, disposal of C\&D waste, rate of measuring waste quantities, and the responsibility of waste disposal. The second stage is concerned with sustainable contract, It explores wither contract and/or project delivery method influence green and traditional projects differently. This stage is divided into two parts; first part for exploring how sustainable contract is different and second part for developing a Contractual Relation Guidelines (CRG). Since the issue of sustainable contracts is considerably new and still under investigation even in developed countries so it was essential to obtain information from multiple resources such that literature reviews, reports and real practice. As a developing country real practice of sustainability in general is very limited in Egypt, so it was not possible to survey a representative sample as in the first stage. Instead structured interviews based on a well-developed questionnaire were conducted with the relevant stakeholders in 9 international and national construction firms. The firms were chosen as the ones involved or consider involving in sustainable construction projects; hence they provide the appropriate environment to explore the sustainable contract related issues. Table (1) displays firms` and interviewees` information. In addition more information about sustainable contracts was extracted from vast literature review including case studies and reports. Based on the findings from the different resources in the first part, the research in the second part establishes a CRG to be used by different stakeholders for developing a sustainable contract for the green project in Egypt. 
Table 1: Profile of the surveyed firms in the second stage

\begin{tabular}{lcccc}
\hline & Firm Specialty & Project Type & Interviewee`s position & $\begin{array}{c}\text { Interviewees years of } \\
\text { Experience }\end{array}$ \\
\hline $\mathbf{1}$ & General construction & All types & General manager & 30 \\
$\mathbf{2}$ & Commercial Construction & Office buildings & President & 35 \\
$\mathbf{3}$ & Commercial Construction & All types & Owner & 32 \\
$\mathbf{4}$ & Building construction & Buildings & President & 50 \\
$\mathbf{5}$ & General construction & All types & Owner & 13 \\
$\mathbf{6}$ & General contractor & All types & Sustainability coordinator & 19 \\
$\mathbf{7}$ & Consultant & Office buildings & Lead Coordinator & 11 \\
$\mathbf{8}$ & Civil construction & Site work & Project manager & 15 \\
$\mathbf{9}$ & General contractor & Office buildings & General manager & 39 \\
\hline
\end{tabular}

\section{V.}

\section{CWM in contracts in Egypt}

FINDINGS AND DISCUSSION

Data gathering and findings in the first stage of the research are devoted to explore how the waste management is addressed in the conventional construction contracts in Egypt. The current research emphasizes on CDWM as one of the sustainability aspects in construction sector and an irritating issue in construction sector in Egypt that need an urgent and powerful solution. On the other hand it emphasizes on the contract as an enforcement and proactive management tool. Therefore the questionnaire explored these aspects through the following questions; 1-how the contract clauses cover the issue of CDWM 2-how the contractors get rid of the waste from their projects; 3-How often the waste quantities are calculated in their projects. And 4-who's responsible for waste disposal. "The majority of the respondents $(99 \%)$ agreed that the contract does not include any detailed clauses regarding CDWM and it just states that waste removing is the contractor responsibility. So the contractor`s management of the generated waste is not according to any contractual obligations, it is rather according to what benefits him practically and economically. This is clearly observed in Fig. 1, Fig. 2 and Fig. 3 which display the responses to the second, third and fourth questions respectively. Fig. 1 shows that in the majority of the projects (62\%) the waste is just moved to the nearest dump site without classification, and $13 \%$ of the projects classify the waste then move it to the nearest dump sites. It also reveals that in $15 \%$ of the projects the waste is classified and part of it is sold, such that steel waste, before dumping it legally. On the other hand $10 \%$ of the projects just move the waste from site and dump it illegally anywhere. The last percentage is promoted to increase taking into account how difficult to confess of doing an illegal action. Fig. 2 represents the respondents' answers for how often the waste quantities are calculated. The choices were: daily, weekly, monthly, whenever it is necessary, or not at all. The answers revealed that $42 \%$ of the projects do not calculate the quantity of the generated waste and $17 \%$ does it occasionally which means that almost $70 \%$ of the projects have either no plan or no records for the quantities of the generated waste. On the other hand $31 \%$ of the sampled projects do the calculations periodically. It is worthy to mention that in questions 2 and 3 the respondents insure in their remarks that in addition to the week practice of CDWM , none of the above practices are mentioned in the contract either waste classification or the periodical calculations of the generated waste. However, it occurs according to the contractor`s practical and economical benefits.

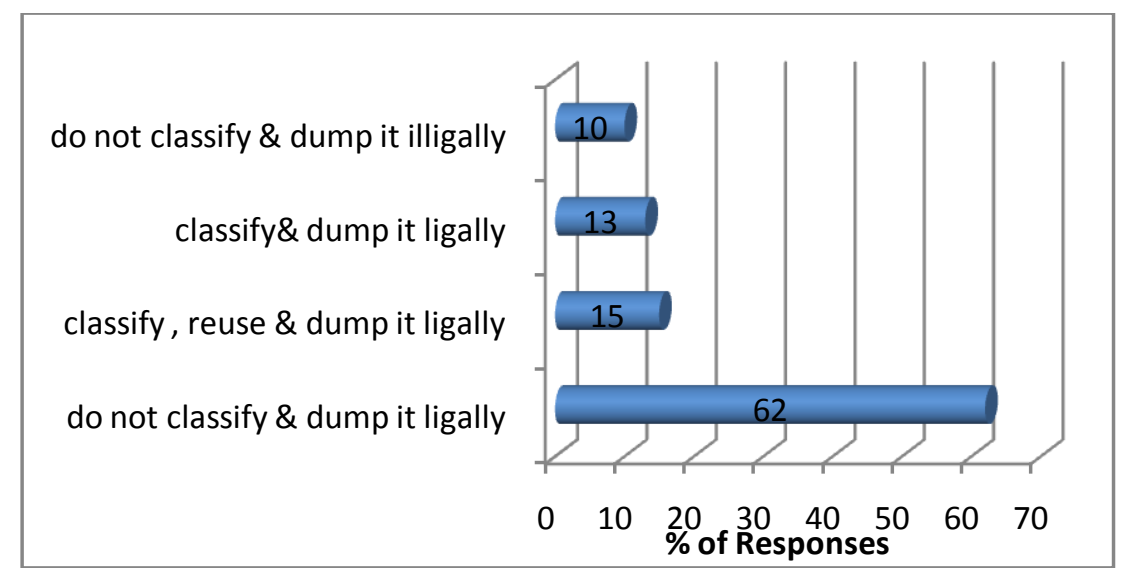

Figure 1: construction waste disposal practices in construction projects in Egypt 


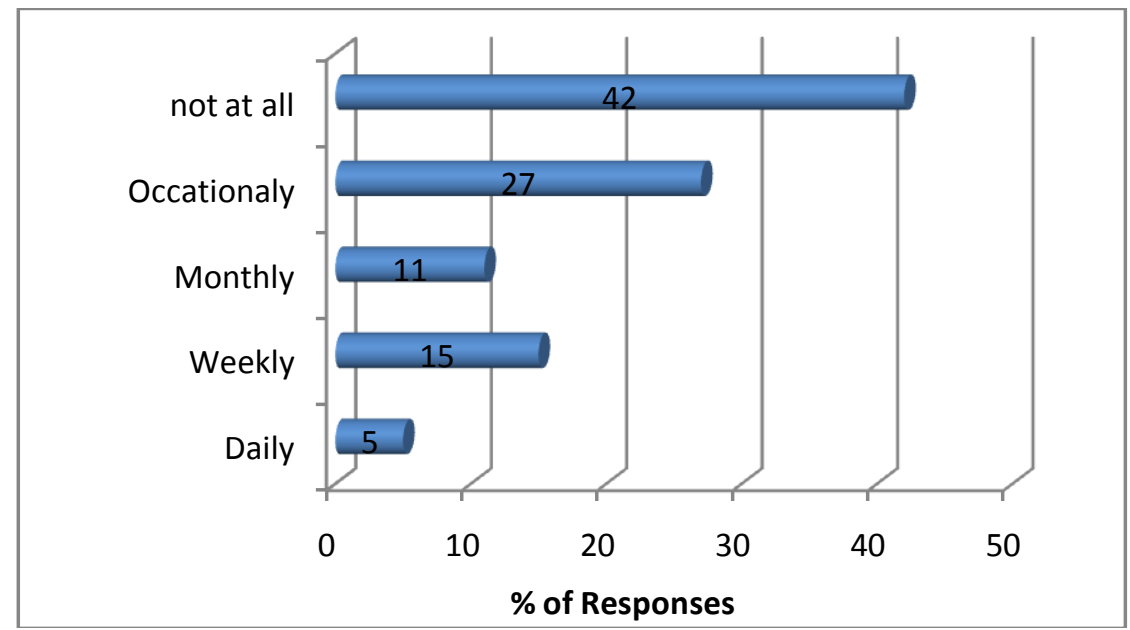

Figure 2: rates of calculating construction waste quantities in construction projects

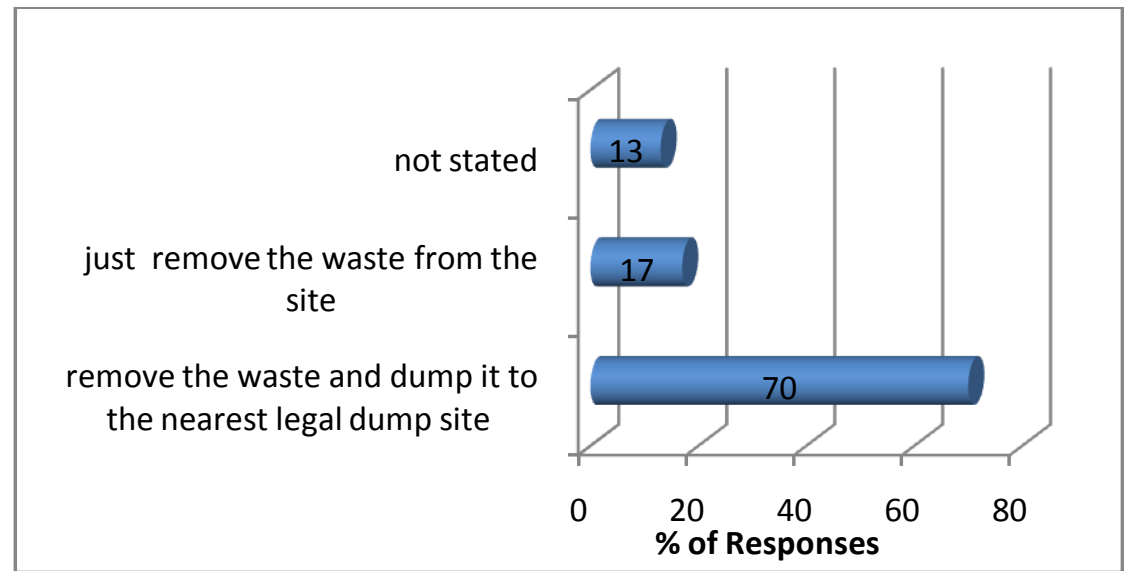

Figure 3: waste disposable responsibility in the contract clauses

Fig. 3 displays the responses of the fourth questions as the following: $70 \%$ of contracts include a clause that assigns the responsibility for removing the waste from the site and moving it to the nearest dump site to the contractor. On the other hand $17 \%$ of the respondents agreed that waste disposal responsibility is not stated in the contract which reflects a total disregarding of this issue on the construction contracts, While $13 \%$ agreed that contract clauses just determine the contractor `s responsibility for removing the waste from the site without any obligations of how and where to dump it. This implies that a sum of $30 \%$ or one third of the contracts of the surveyed projects does not include any commitments regarding CDWM, and in the other 70\% it is limited to dumping the waste.

Results from the first stage in the research reveals a real gap between the academic and regulatory level represented in national studies, Egyptian Rating System and codes developments and the practice level represented in the contract formation.. The findings above clearly support the research argument that the formation of the contract as a proactive and enforcement tool should include sustainable relevant clauses to enhance CDWM implementation for the sustainable contract in Egyptian projects.

\section{Sustainable contracts}

\section{1: The choice of contract type}

The contributions of the research in sustainable contract formation started in second stage by wondering wither the contract type and/or project delivery method has an influence on the sustainable contract. Interviews were conducted with 2 general managers, 2 owners, 1 project manager, 2 construction firms` chairmen and 2 sustainable coordinators as shown in table 1 . The questionnaire is designed to reach answers for the following questions; 1-what matters contract type or project delivery method? , 2- what is the influence of project characteristics on contract type and PDM `s choice?, and 3- what factors influence the choice of contract type and/or project delivery method? In responding to the first questions, as displayed in Fig 4, 7 out of 9 interviewees agreed that booth contract type and PDM are of the same importance when considering sustainability, while one interviewee chose contract type and other one chose PDM. 


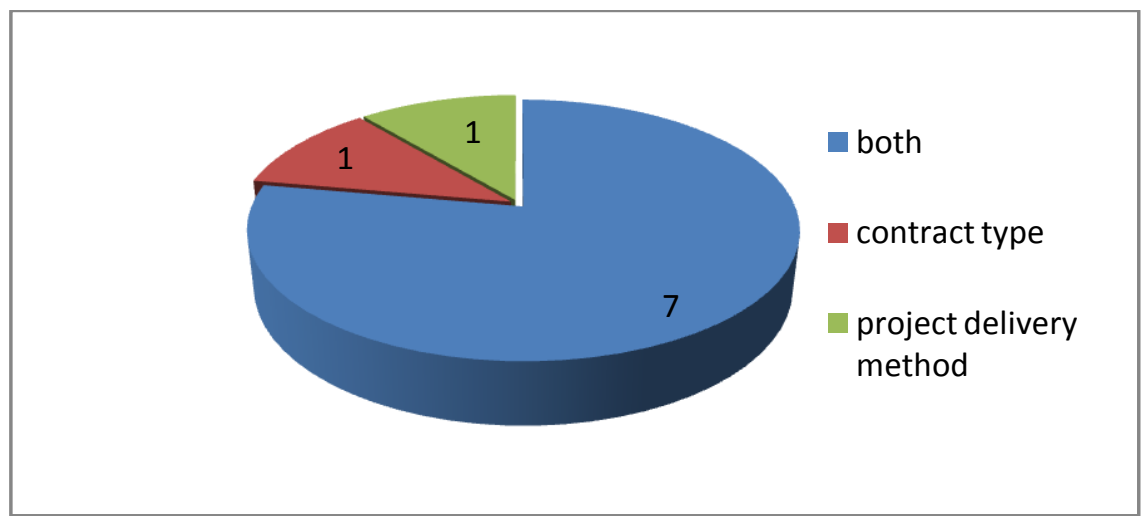

Figure 4: the importance of contract type and/or PDM for sustainable construction

The research is adopting Michael S. 2009 [10], classification and analysis where it combined contract types and project delivery method in the same classification and studied the influence of the conventional project characteristics on them. This study is adopted to demonstrate the main classification of contracts types and project delivery methods and build on it as a base of comparison. It identifies the contract classification by two models and refers to the contract type as Compensation Scheme model and to the project delivery method as Governance structure model

\section{Compensation Scheme model (contract type) includes three archetypes:}

- Stipulated sum or lump sum (outcome): this scheme concentrates on outcomes to determine compensation.

- Cost plus a fee (salary): this scheme concentrates on a "salary" style of compensation. Agents are paid for the effort of producing.

- Guaranteed max price: with cost savings/sharing (incentive) this scheme proposes a small "salary" coupled with a bonus based upon the overall performance of the firm.

\section{Governance structure model (Project delivery method) includes three archetypes:}

- Plans and specs contract (Conventional Design, Bid and Build): the structure attempts to mimic a commodity market, the participants are seen as buyers and sellers of component pieces.

- The construction management contract (hybrid): The designer and the construction manager are distinct but both are seen as professionals. This contract type encourages interaction between the critical members of the project management structure

- The design/ build contract (hierarchy): the owner purchases a completed project from an entity that supplies both the design and the construction services. From the owners perspective he is dealing with a vertically integrated firm. Here the designer and the contractor are responsible for each other's actions

Michael S. 2009 studied the influence of project characteristics such that complexity, uncertainty and asset specificity on contract type choice. Research results are presented in Fig. 5 and show that, In general, as complexity increases asset specificity, uncertainty, and information asymmetry increases, while the accuracy of performance measures decreases. Consolidating Tables 1 and 2 in terms of complexity results in the set of relationships described in Table 3, Fig. 5 is a snapshot of the three tables that summarizes the relation between project complexity and the two approaches of contracts.

Table 1. Governance Structure Model

\begin{tabular}{lccc}
\hline Governance structure & Uncertainty & Asset specificity & Frequency \\
\hline Plans and specs & Low & Low & Low \\
Construction management & High & Medium & Medium \\
Design-build & High & High & High \\
\hline
\end{tabular}


Table 2. Compensation Scheme Model

\begin{tabular}{lcc}
\hline $\begin{array}{l}\text { Compensation } \\
\text { scheme }\end{array}$ & $\begin{array}{c}\text { Information } \\
\text { asymmetry }\end{array}$ & $\begin{array}{c}\text { Performance } \\
\text { measurement }\end{array}$ \\
\hline Lump sum & $\mathrm{NA}^{\mathrm{a}}$ & Exact \\
Cost plus & Medium & Imprecise \\
GMP & High & Imprecise \\
\hline
\end{tabular}

Table 3. Relationship between Governance, Compensation, and Complexity

\begin{tabular}{lccc}
\hline & \multicolumn{3}{c}{ Complexity } \\
\cline { 2 - 4 } & Low & Medium & High \\
\hline Governance & Plans and specs & CM & DB \\
Compensation & Lump sum & Cost plus & GMP \\
\hline
\end{tabular}

Figure 5: The influence of conventional project characteristics on contract type (Source: Michael S.Puddicombe 2009)

The current research investigated how uncertainty and complexity of the sustainable projects influence the two approaches of contract in the second question of the interview. In general sustainable project are of a complex and uncertain nature, therefore the question here is how to rank the contract types according to the level of project's uncertainty and complexity. The interviewees were asked to give scores to the contract type and PDM choices according to the uncertainty and complexity level of the sustainable project. The interviewees chose from a 3 - point scale answers that range from $1=$ low to $3=$ high. The answers collected and analyzed then the average score of the 9- interviewees` answers displayed and ranked in an increasing order in Table 2. The relation between the two contract approaches and the sustainable project's uncertainty are presented in Fig. 6. The figure shows that, for the contract type (compensation approach) the G.M.Price gained the highest score, which implies that this contract type would be chosen for the highest level of uncertainty and complexity followed by Lump sum then Cost plus. For the PDM (governance approach) the highest score was for DB, which is ranked as the most appropriate for the high level of uncertainty and complexity followed by $\mathrm{CM}$ then DBB. This finding is supported by literature review findings where it is concluded that in green construction projects the design-build delivery system is the most appropriate [11] and Design and build is still one of the most prevalent procurement method [1]. Comparing these results with Michael S. 2009`s results for conventional projects reveals that, with respect to the PDM (governance approach), the influence of sustainable project characteristics on its choice is almost the same as in conventional project regarding uncertainty and exactly the same regarding complexity. However, with respect to the compensation scheme type of contracts, interviewees` answers showed some difference from Michael`s results. Unlike Michael`s study which concluded that the lump sum contract is appropriate for low complex conventional projects, this contract type is ranked as the second best choice for sustainable projects regarding complexity and uncertainty. This could be attributed to the uncertain and complex nature of the sustainable projects that makes the lump sum type is more appealing to other stakeholders to transfer the risk of project complexity and uncertainty to the contractor.

Table 2: the influence of sustainable projects characteristics on contract type

\begin{tabular}{ccc}
\hline & complexity & uncertainty \\
\hline Compensation & & \\
cost plus & 2.11 & 1.89 \\
lump sum & 2.22 & 2.11 \\
G.M.Price & 2.33 & 2.44 \\
Governance & & \\
D.B.B & 2.11 & 1.89 \\
CM & 2.38 & 2.13 \\
D.B & 2.56 & 2.33 \\
\hline
\end{tabular}




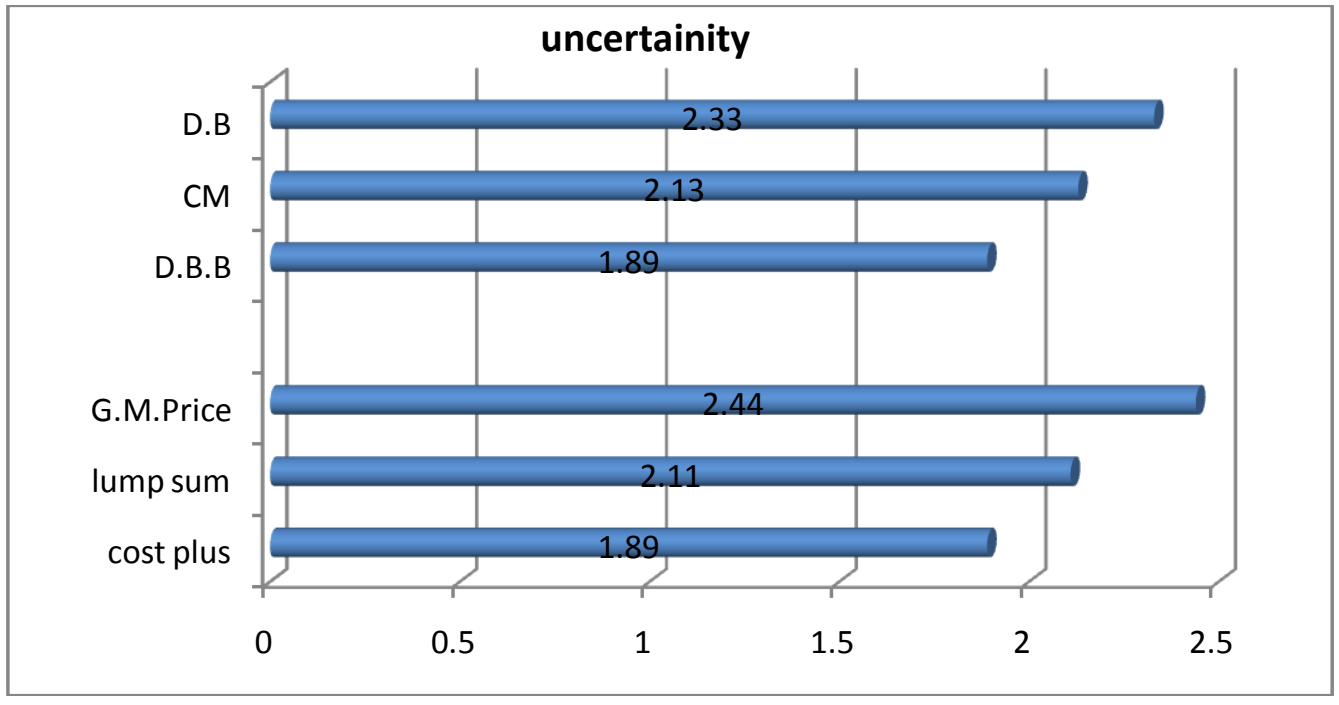

Figure 6: The relation between the two approaches of contracts and uncertainty in sustainable project

\subsection{Factors influencing sustainable contract}

To provide a base for developing and formulating the CRG, a number of relevant factors to contract type and/or PDM have been examined as well. 12 common factors were identified through reviewing the literature for conventional projects and the third question in the questionnaire examines how these factors influence the choice of contract type and/or PDM for sustainable projects. Interviewees were asked to choose from a 3- point scale answers that range from 1=low to $3=$ high. Responses from the 9 interviewees are collected, analyzed and plotted in Fig 7. The average score for each factor is calculated for contract type and PDM. To identify the factors that most affect the choice of both contract approaches, the scores from each interviewee for the two approaches were added and then the average of the total for each factor is calculated, results are presented in Table 3. In Fig. 7 the average of the total scores of both contract approaches is ranked increasingly and plotted against the average scores for contract type and PDM. The figure and the table display that most of the factors keep the same rank either ranked by the average of the total score or ranked by the average score for each approach. However, it worth noticing that "Project location" and "Portion of subcontracting work", do not follow the same trend where they have a higher rank in their influence on the choice of contract type than PDM, This is because of the sensitivity of these two factors for the contract where "project location" may affect the cost in sustainable project and the "portion of subcontracting work" is crucial in such projects. Also despite that "project duration" and "project type" follow the same trend; they were seen to influence the choice of PDM more than the choice of contract type.

"Client demand", "past experience with similar projects", "stakeholders' involvement" are the dominant influencing factors for the two contract approaches where they all have a score $>2.5$ in a 3-point scale and it is worth noticing that "client demand" recorded the most influencing factor in sustainable project. This result is totally complying with what has been reviewed in literature for sustainable projects, where it emphasizing the importance of client demands and how it should be clear for this type of projects and its consequences on his commitment during the project lifecycle [12]. Also the need for specialist or professionals with previous experience and the early involvement of the stakeholders are all considered of high priority in sustainable construction literature [13]. In addition the Lack of communication and interest amongst project team members and Lack of expressed interest from client and market demand were found to be highly ranked obstacles encountered during green building project management [11]. It is also highlighted that the design phase in green construction must include all key external stakeholders, including surrounding property owners and other community representative [8].

"Work scope definition" comes on the top of the second group of factors that have scores $<2.5$ and $\geq$ 2 , and indicating a medium influence on the choice of both approaches. It is interesting to notice that this group includes "portion of subcontracting work", "risk and safety hazard" and "service provider" where the literature referred to all of them as considerable factors for sustainable construction but when it comes to the choice of contract approach they hold less degree of importance.

The third group of factors which has scores $<2$, their influence were identified to be low so for sustainable projects it is agreed that the less influential factors on the choice of the two approaches of contract are "project duration", "measuring performance" and "project location" respectively. 
Table 3: Factors influencing the choice of contract type and/or project delivery method

\begin{tabular}{lccc}
\hline \multicolumn{1}{c}{ Factors } & $\begin{array}{c}\text { Contract } \\
\text { type }\end{array}$ & $\begin{array}{c}\text { Delivery } \\
\text { method }\end{array}$ & $\begin{array}{c}\text { Average of } \\
\text { total score }\end{array}$ \\
\hline project location & 1.89 & 1.56 & 3.44 \\
Measuring performance & 1.78 & 1.78 & 3.56 \\
project duration & 1.89 & 2.00 & 3.89 \\
service provider & 2.00 & 2.00 & 4 \\
\hline contract price evaluation & 2.22 & 2.22 & 4.44 \\
risk/safety hazard & 2.22 & 2.22 & 4.44 \\
Portion of subcontracting work & 2.34 & 2.22 & 4.56 \\
project type & 2.33 & 2.44 & 4.78 \\
work scope definition & 2.44 & 2.44 & 4.67 \\
stakeholders involvement & 2.56 & 2.56 & 5.11 \\
\hline past experience with similar projects & 2.67 & 2.67 & 5.33 \\
Client demand & 2.88 & 2.88 & 5.75 \\
\hline
\end{tabular}

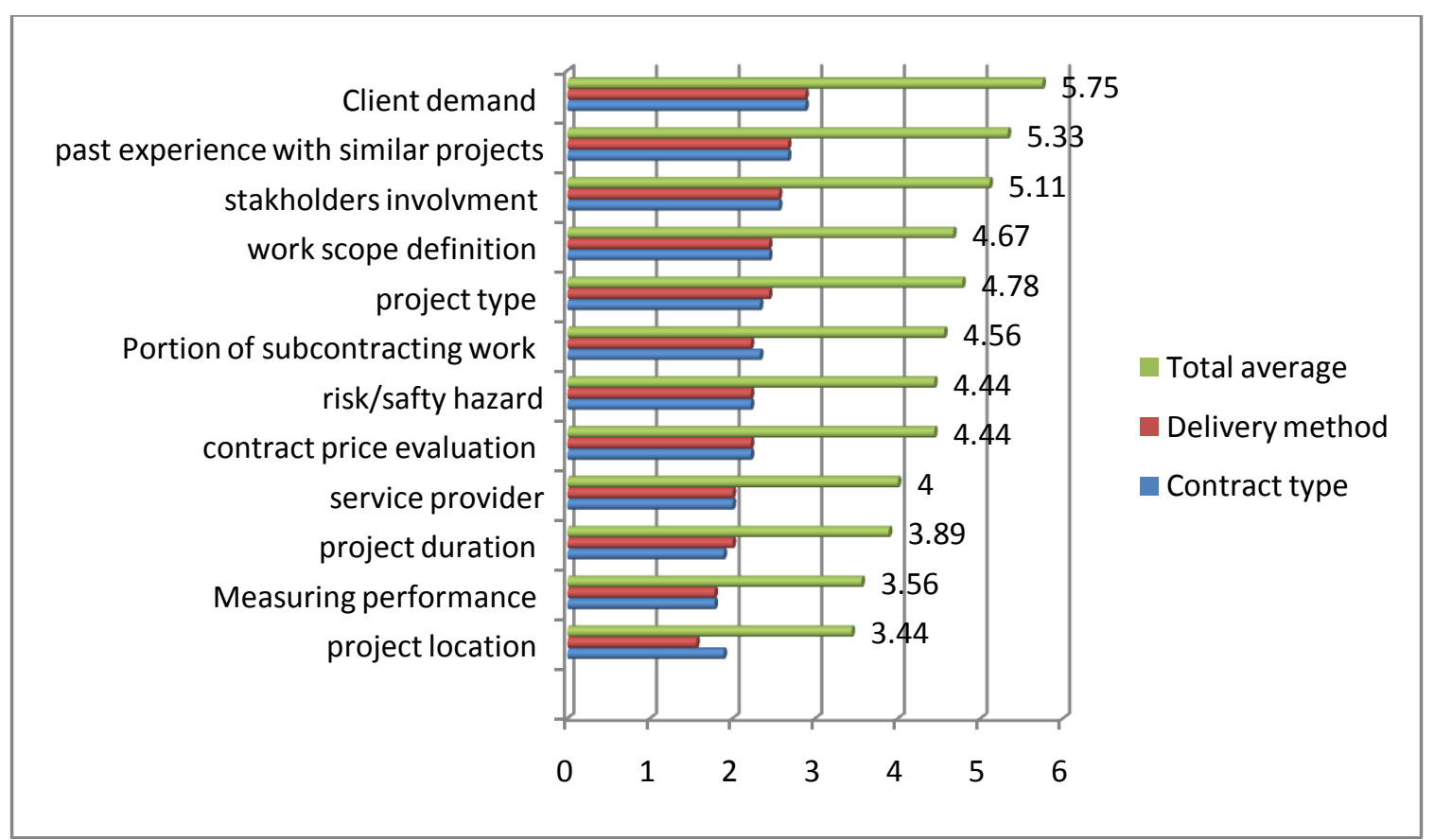

Figure 7: The influence of sustainable project related factors on the two approaches of contracts

\section{DEVELOPING CONTRACTUAL RELATION GUIDLINE (CRG)}

The framing of appropriate contract clauses could be complicated. It is not always easy to adequately define a sustainability objective in contractual terms. Even if you can, there may be little loss suffered by the developer for failure by the contractor to comply with such a term and as a result the provision may lack teeth [14]. Therefore this part of the second stage does not introduce a standard form for a contract however it is dedicated to developing a contractual relation guideline CRG to enable the relevant stakeholders of formatting the appropriate sustainable contract that fits their projects. Moreover it is oriented particularly to the contract that considers CWM.

The CRG is based on three main findings from the current research, which also can be considered as the limitations of the proposed guidelines. The first one is the contracting approach; according to the findings from the interviews and from the literature the most appropriate contract type and PDM are GMP and DB respectively. The second one is the influencing factors; by emphasizing the highly ranked ones. The last one is the required clauses and documents in the contract to successfully implement CWM. The research is adopting the DB contract relation diagram -as an illustrative tool for stakeholders- from the American Institute of 
Architect AIA Contract Documents, the Industry standard, which has been recently issued for conventional projects in June 2013 [15]. It is displayed in Fig. 8

Design-Build

\section{Key Attributes:}

- Owner enters into a contract with a single entity Design- Builder

- Design-Builder is then obligated to both design and construct the project

- Owner may also hire a Consultant to assist Owner in working with Design- Builder

- Design -Builders then enter into contracts with Architect and/or construction contractor(s), if necessary

- Design - builder may be

- A developer or single purpose entity (design and construction in one shop)

- An architect - led organization

- A contractor - led organization (most often the case)

The GMP as the compensation approach of contract type is proposed depending on what have been reached earlier and the advantages presented in table 4 promotes this type for sustainable projects where it allows the involvement of stakeholders and for contractor to work with the owner. In addition it suits the high level of uncertainty combined with sustainable projects where plans and specs do not have to be "bullet proof" and changes can be made. It also allow of risk sharing among the main stakeholders.

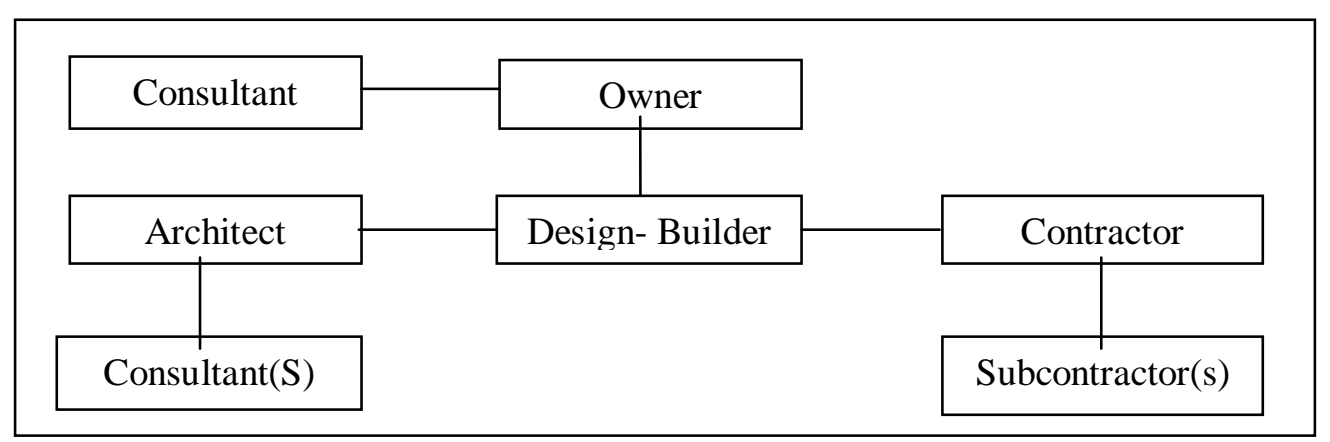

Figure 8: AIA Design - Build Contract Relationship

Table 4: Guaranteed Maximum Price contract

\section{Guaranteed Maximum Price}

\begin{tabular}{|c|c|}
\hline Advantages for Owner & Disadvantages for Owner \\
\hline Can specify exact requirements & $\begin{array}{l}\text { Owner shares some of the cost risks and savings } \\
\text { with Contractor }\end{array}$ \\
\hline $\begin{array}{l}\text { Price competition from multiple, pre-qualified } \\
\text { bidders. }\end{array}$ & $\begin{array}{l}\text { Amount of savings depends upon owner's } \\
\text { participation in decision-making. }\end{array}$ \\
\hline \multicolumn{2}{|l|}{ Freedom to make changes (with some cost risk). } \\
\hline \multicolumn{2}{|l|}{ Plans and specs do not have to be "bullet proof." } \\
\hline \multicolumn{2}{|l|}{ Change order process is non-adversarial } \\
\hline \multicolumn{2}{|l|}{ Can start from preliminary plans } \\
\hline \multicolumn{2}{|l|}{ There is a firm ceiling on the price. } \\
\hline \multicolumn{2}{|l|}{ Contractor works with owner. } \\
\hline $\begin{array}{l}\text { Contractor shares cost risks and savings with } \\
\text { Oxwner } \\
\text { Actual cost records are open. }\end{array}$ & \\
\hline
\end{tabular}

The above mentioned three findings are the drives of the developed CRG that the research introduces to stakeholders to consider and build on them in the process of sustainable contract formation. CRG is presented in a simple tabulated form in table 5 where each column illustrates one of the three main drives 
Table 5: Contractual Relation Guide (CRG) for sustainable contract focusing on CWM

\begin{tabular}{|c|c|c|}
\hline $\begin{array}{l}\text { Factors to be Considered } \\
\text { when Negotiating and } \\
\text { Drafting Contract }\end{array}$ & $\begin{array}{l}\text { Sustainability clauses and documentations in } \\
\text { the Contract }\end{array}$ & $\begin{array}{l}\text { Recommended } \\
\text { Contractual Approaches }\end{array}$ \\
\hline $\begin{array}{l}\text { - Stakeholders } \\
\text { communication } \\
\text { - Clear and } \\
\text { specific client demand } \\
\text { - Early } \\
\text { stakeholders involvement } \\
\text { - Precise work } \\
\text { scope definition } \\
\text { - Seeking } \\
\text { sustainability } \\
\text { professionals and } \\
\text { experienced contractors } \\
\text { - Promotion for } \\
\text { training and awareness } \\
\text { towards sustainability and } \\
\text { CWM in particular. } \\
\text { - Considering the } \\
\text { International construction } \\
\text { documents which based } \\
\text { on industry-prepared } \\
\text { standard forms such that : } \\
\text { FIDIC (International } \\
\text { Federation Consulting } \\
\text { of Jef } \\
\text { Engineers) and Joint Contracts } \\
\text { Tribunal) }\end{array}$ & $\begin{array}{l}\text { Clauses } \\
\text { - Comply with the environmental } \\
\text { laws and regulations } \\
\text { - Comply with the related codes : } \\
\text { green building code and solid waste } \\
\text { recycling code } \\
\text { - Comply with the prerequisites } \\
\text { regarding CWM in the Egyptian Pyramid } \\
\text { Rating System } \\
\text { - } \quad \text { specify the types of equipment to be } \\
\text { used for CWM } \\
\text { - include a provision for the use of } \\
\text { recyclable material } \\
\text { - include a provision for the in-site } \\
\text { recycling requirements } \\
\text { - Identify and allocate the related risk } \\
\text { - Clearly define responsibilities for } \\
\text { different stakeholders } \\
\text { - incorporate incentives, rewards and } \\
\text { bonuses } \\
\text { - incorporate penalties for non } \\
\text { compliance } \\
\text { Documentations : } \\
\text { - Prepare a waste management plan, a } \\
\text { plan that demonstrate in details how , when } \\
\text { and by whom the project waste will be } \\
\text { managed } \\
\text { - } \quad \text { Prepare a cost estimate for CWM }\end{array}$ & $\begin{array}{l}\text { For } \quad \text { Compensation } \\
\text { approach ( contract type): } \\
-\quad \text { Guaranteed } \\
\text { Maximum Price }\end{array}$ \\
\hline
\end{tabular}

\section{CONCLUSION}

The construction sector in Egypt has started to embrace sustainability principles into their laws and regulations and by issuing the Egyptian Pyramids Rating System, national studies and reports as well as developing related codes. However there is a long way to go to reach a satisfactory practice level. The research focused on CWM as one of sustainability principals and on contract as one of the proactive and enforcement management tools. The diagnosis for the status of CWM by a field survey applied in Great Cairo insured that CWM in construction contracts is either disregarded or limited to waste disposal to the dump site. To bridge the gap between the legislation and academic levels and the practice level, the research developed a Contractual Relation Guidelines CRG. The CRG is based on three main findings from the current research. The first is the appropriate contractual approaches, where it is found through interviewing experts that booth contract type and PDM are of the same importance when considering sustainability. GMP and DB are the most appropriate regarding both compensation and governance approach of contracts respectively. The second drive of the CRG is the influencing factors that were examined through the same interviews and ranked to show that the most influencing factors on sustainable contracts are "client demand" , " past experience with similar projects "and "stakeholders involvement". The third drive is the required contract"s clauses and documents for CWM implementation which collected from a vast literature review. The developed CRG introduces the three drives to stakeholders to consider and build on them in the process of sustainable contract formation. And it is presented in a simple tabulated form to be easy to follow.

There is limitation for this study; one of which the interviews results are from the perspective of the owners, project managers and sustainability professionals while contractors perspectives were absent. so interviews with contractors could be conducted and might result in different perspectives. Also sustainability term in this research is limited to CWM however enlarging it to its wide meaning will result in more comprehensive CRG. 


\section{REFERENCES}

[1] Ron Plascow, Partner, Mills \&Reeve LLP," Construction and Sustainability from Lawyer's Perspective", National Head of Construction and Engineering, www.universitybusiness.co.uk, 2011

[2] Frank Mills, Tom Lawrence, Ashish Rakheja, and Abdel-Kader Darwiche, Green Building Practices around the world , ASHRAE Journal , January 2012

[3] E. Sabry, Developing a Model for Wast Management System for Construction Industry in Egypt, Mattaria college of Engineering, Helwn University, Mattaria „Egypt, 2010.

[4] Country Report of the Solid Waste Management in Egypt ", The Regional Solid Waste Exchange of Information and Expertise network in Mashreq and Maghreb countries, July 2010.

[5] Construction and Demolition Debris Management, Solid Waste Management Privatization Procedural Manual, U.S. Agency for International Development.

[6] M.s. Abdelhamid, "Construction and Demolition Waste Management: Towards Strategic Vision", Ain Shams University International Conference on Environmental Engineering, Cairo, Egypt.2007.

[7] S. H. Park, , Whole Life Performance Assessment : Critical Success Factors, Journal of Construction Engineering and Management, ASCE, 1146, November 2009.

[8] L. B. Robichaud and V. S. Anantatmula, , Greening Project management practices for Sustainable Construction , Journal of Management in Engineering , ASCE ,48, January 2011.

[9] H. S. Cha, J. Kim, and J. Han, Identifying and Assessing Influence factors on Improving Waste Management Performance for Building Construction Projects , Journal of Construction Engineering and Management , ASCE ,647 ,July 2009.

[10] M. S. Puddicombe, , Why Contracts: Evidence, Journal of Construction Engineering and Management , ASCE, 675, August 2009.

[11] B. Hwang and J. S. Tan ,Green Building Project Management: Obstacles and Solutions for Sustainable Development", Sustainable Development, Sust. Dev., Published online in Wiley InterScience, (www.interscience.wiley.com) DOI: 10.1002/sd.492, 2010.

[12] S. Kubba, green construction project management and cost oversight (Architectural Press. 2010 Elsevier Inc).

[13] M.Aid, sustainable development and project management (LAB LAMBERT Academic Publishing , 2009)

[14] J. Scott Russell, Sustainable development in construction contracts, Inside Housing Sustainable Development, 18th June 2008.

[15] American Institute of Architect AIA Contract Documents, the Industry standard. Contract Relationship diagrams , June 2013 